\title{
Research contributions from the First Cancer Center Survivorship Research Forum
}

\author{
Anne H. Blaes ${ }^{1,2}$ \\ Received: 24 September 2021 / Accepted: 6 November 2021 / Published online: 2 February 2022 \\ (c) The Author(s) 2022
}

Keywords Cancer survivorship $\cdot$ Patient reported outcomes $\cdot$ Health care delivery

Decades of continuous improvements in cancer treatment have led to a substantial increase in the longevity of individuals with cancer forecasted to grow to over 22 million by 2030 [1]. However, cancer does not end with the end of treatment. In the aftermath of a cancer diagnosis and its treatments, many individuals require long-term care and attention related to chronic issues such as fatigue, cognitive changes, cardiovascular disease, metabolic syndrome, and secondary cancers [2,3]. Individuals also encounter stress in their work, finances, and insurance because of their cancer history. They experience anxiety, depressive symptoms, and fears related to recurrence, treatment exposures, new cancers, or existential concerns that extend to their families. Bringing together cancer survivor researchers, clinical specialists and patient advocates, with a focus on health care delivery, the use of technology and risk stratification is imperative in enhancing the exchange of ideas, mentoring junior faculty and researchers. The Cancer Center Survivorship Research Forum facilitate the research and implementation of a cancer survivor research agenda [4-6].

After the National Cancer Institute's Biennial Cancer Survivorship Conference and the American Society of Clinical Oncology's (ASCO) Cancer Survivorship Symposium were

Jewett, P.I., Vogel, R.I., Ghebre, R. et al. Telehealth in cancer care during COVID-19: disparities by age, race/ethnicity, and residential status. J Cancer Surviv (2021). https://doi.org/10.1007/ s11764-021-01133-4. Paper was inadvertently published online November 20, 2021. This paper is part of this Special Section.

Anne H. Blaes

Blaes004@umn.edu

1 Masonic Cancer Center, University of Minnesota, Minneapolis, MN, USA

2 Hematology/Oncology, Cancer Survivorship Services and Translational Research, University of Minnesota, Minneapolis, MN, USA discontinued in 2018 due to financial constraints and difficulties in achieving goals related to connecting with primary care, it has been difficult to connect cancer survivorship researchers and clinicians together with advocates to foster such exchange, collaboration, and innovation. Aligned with the mission of each National Cancer Institute-designated Cancer Center, we hosted the first Cancer Center Survivorship Research Forum April 15-16, 2021 (https://ccsrf.umn. edu). This platform, to be continued biannually for at least the next 8 years, provided a unique and timely opportunity to bring together clinicians, researchers, patient advocates, and professional societies spanning the disciplines of oncology, radiation oncology, psychooncology, nursing, exercise physiology, primary care, and rehabilitation around the shared goal of improving the health and healthcare delivery of cancer survivors.

The aim of the Journal of Cancer Survivorship: Research and Practice is to provide and promote a multidisciplinary platform aimed at improving the understanding, care, and care delivery of cancer survivors. Within this special section of the journal, researchers from the first Cancer Center Survivorship Research Forum conference highlight some of the work presented and discussed. The themes of the conference focused on innovations in healthcare delivery, use of technology to extend and enhance care, implementing patient-generated data, building an ecosystem of care, and addressing ongoing needs for unique populations. The second aim of the conference was to facilitate collaboration and exchange of research ideas.

The cancer survivorship landscape is changing as cancer patients survive longer, and the baby boomers age $[5,7]$. Not only will this growing number of individuals with ongoing care needs threaten to exceed the capacity of our healthcare system but high-quality patient-centered care will also require better multidisciplinary cooperation among patients, primary care, oncology providers, and 
specialists for all facing this diagnosis [8]. As a result, there is a great need for new models of care delivery for cancer survivors $[9,10]$. Stan and colleagues describe one new model of care in breast cancer survivors, using existing technology to aid in facilitating coordinated survivorship care [11]. The authors describe a pilot study testing the feasibility of mobile application for breast cancer survivors integrated with the electronic health record; 23 individuals tested the intervention with $100 \%$ engagement and $59 \%$ reporting toxicity assessments. They demonstrated that overall this mobile application was feasible and acceptable for patients to use and report toxicity information and patient-reported outcomes. Additionally, patients were able to receive educational materials based on toxicities, and ultimately this integrated application did not result in an increased burden on the healthcare team, with only $4.3 \%$ of messages escalating clinical concerns requiring patient contact. This pilot study was done in predominantly white, married women; thus, further work is needed on a broader, more diverse, population. Utilizing technology and partners outside the traditional walls of healthcare may provide opportunity to enhance care, as we have all learned from the rapid implementation of telehealth since the COVID pandemic. Remaining aware of how to provide equitable care using telehealth remains essential and needs to be continually evaluated as highlighted by Jewett and colleagues [12] where there were differences in the utilization of telehealth (video visit versus telephone encounter) based on race, geography, and ethnicity.

Patient-generated data provides an opportunity to allow the capture of patient perspectives during both a clinic visit and outside of a clinical encounter. Previous literature suggests capturing patient-reported outcomes can result in greater satisfaction with care, fewer emergency department visits, improvements in overall survival, and may help in predicting treatment outcomes and complications [13, 14]. Further research, however, is needed to truly understand how to implement and utilize these data in an efficient, responsive, and timely manner. Mazariego and colleagues used a modified Delphi approach to provide guidelines for the implementation of patient-reported outcomes, allowing clinicians and researchers a platform for which to build upon in the capture of patient-generated data [15]. Assessing readiness, addressing barriers, and developing implementation strategies are imperative in the successful implementation of PROs.

Finally, in order to enhance the care for cancer survivors, we must adapt and implement additional models for educating healthcare providers and patients about the longterm health needs of cancer survivors in unique and novel ways [16, 17]. Klemp and colleagues describe a pilot study examining tele-monitoring in rural cancer survivors [18]. This original research article extends cancer survivorship education and subsequently care by utilizing technology and mobile applications integrated within the health record. In a subsequent research manuscript, Jayzona and colleagues describe a model of cancer survivorship education for healthcare providers emphasizing the importance of education within continuing medical education around various topics in cancer survivorship [19].

Aligned with the mission of each National Cancer Institute-designated Cancer Center in which cancer survivorship care remains a priority, the Cancer Center Survivorship Research Forum will continue on a biannual basis hosted by rotating NCI Cancer Centers (currently planned for 2023 at Stanford and 2025 at University of North Carolina). Its inaugural virtual meeting had 236 attendees from 32 states within the USA, and 5 countries. With $100 \%$ of attendees improving their knowledge, skills, and strategies in cancer survivorship, and $70 \%$ making new contacts clinically and research based, CCSRF will provide a vehicle to disseminate health services research to relevant stakeholder communities and to facilitate the engagement of the oncology community and its interdisciplinary network of researchers and providers for future collaborations. These collaborations will provide another venue to develop and disseminate tools to support the community of cancer survivors, facilitate the mentorship and networking of future facilities, and aid in the development of programs that improve the quality, education, effectiveness, and innovation of cancer survivorship healthcare. The Journal of Cancer Survivorship is pleased to communicate certain contributions to the initial meeting.

Acknowledgements We are thankful to our planning committee for their ongoing dedication and enthusiasm in planning this special event. Anne Blaes, MD (committee chair, University of Minnesota), Deborah Mayer, $\mathrm{PhD}$ (committee co-chair, University of North Carolina, Interim Director of NCI's Office of Cancer Survivorship), Catherine Alfano, PhD (Northwell Healthcare), Smita Bhatia, MD (University of Alabama at Birmingham), Jennifer Klemp PhD, MPH (University of Kansas), Lucie Turcotte, MD, PhD (University of Minnesota), Lidia Schapira, MD (Stanford University), Catherine Bender, RN (University of Pittsburgh), Rowena Schwartz (Pharm D, University of Pittsburgh), Karen Pennington, PA (Stillwater Medical Group - Cancer Clinic), Lissa Martinez Huebner (University of Minnesota), Mo Laschen (University of Minnesota).

\section{Declarations}

Conflict of interest The author declares no competing interests.

Open Access This article is licensed under a Creative Commons Attribution 4.0 International License, which permits use, sharing, adaptation, distribution and reproduction in any medium or format, as long as you give appropriate credit to the original author(s) and the source, provide a link to the Creative Commons licence, and indicate if changes were made. The images or other third party material in this article are included in the article's Creative Commons licence, unless indicated otherwise in a credit line to the material. If material is not included in 
the article's Creative Commons licence and your intended use is not permitted by statutory regulation or exceeds the permitted use, you will need to obtain permission directly from the copyright holder. To view a copy of this licence, visit http://creativecommons.org/licenses/by/4.0/.

\section{References}

1. Miller KD, Nogueira L, Mariotto AB, Rowland JH, Yabroff KR, Alfano CM, et al. Cancer treatment and survivorship statistics, 2019. CA Cancer J Clin. 2019;69(5):363-385.

2. Hewitt MGS, Stovall E. From cancer patient to cancer survivor: lost in transition. Washington D.C.: The National Academies Press; 2006.

3. Moskowitz CS, Chou JF, Neglia JP, Partridge AH, Howell RM, Diller LR, et al. Mortality after breast cancer among survivors of childhood cancer: a report from the Childhood Cancer Survivor Study. J Clin Oncol. 2019;37(24):2120-30.

4. Shapiro CL. Cancer survivorship. N Engl J Med. 2018;379(25):2438-50.

5. Rowland JH, Bellizzi KM. Cancer survivorship issues: life after treatment and implications for an aging population. J Clin Oncol. 2014;32(24):2662-8.

6. Chan RJ, Nekhlyudov L, Duijts SFA, Hudson SV, Jones JM, Keogh J, et al. Future research in cancer survivorship. J Cancer Surviv. 2021;15(5):659-667.

7. Alfano CM, Smith T, de Moor JS, Glasgow RE, Khoury MJ, Hawkins NA, et al. An action plan for translating cancer survivorship research into care. J Natl Cancer Inst. 2014;106(11):dju287.

8. Alfano CM, Mayer DK, Bhatia S, Maher J, Scott JM, Nekhlyudov $\mathrm{L}$, et al. Implementing personalized pathways for cancer follow-up care in the United States: proceedings from an American Cancer Society-American Society of Clinical Oncology summit. CA Cancer J Clin. 2019;69(3):234-47.

9. Loonen JJ, Blijlevens NM, Prins J, Dona DJ, Den Hartogh J, Senden T, et al. Cancer survivorship care: person centered care in a multidisciplinary shared care model. Int J Integr Care. 2018;18(1):4, 1-7.

10. Alfano CM, Suarez-Almazor M, Rodriguez MA, Palos GR, Gilmore KR. Innovating the personalization of stratified survivorship care pathways: using a cancer data ecosystem to improve care access, outcomes, efficiency, and costs. J Natl Cancer Inst Monogr. 2021;2021(57):3-9.
11. Stan DLI JW, Ridgeway JL, Johnson KN, Christopherson LA, McColley SM, Brown JK, Phillips SA, Allen SV, Hazelton JK, Ruddy KJ, Haddad TC. Pilot implementation to assess the feasibility and care team impact of an App-based breast cancer survivorship care plan in the oncology practice. J Cancer Surviv. 2021.

12. Jewett PIV RI, Ghebre R, Hui J, Parsons H, Rao A, Sagaram S, Blaes AH. Rapid implementation of telehealth during COVID19: reducing or increasing disparities in cancer care? J Cancer Surviv. 2021.

13. Basch E, Dueck AC, Rogak LJ, Mitchell SA, Minasian LM, Denicoff AM, et al. Feasibility of implementing the patient-reported outcomes version of the common terminology criteria for adverse events in a multicenter trial: NCCTG N1048. J Clin Oncol. 2018;36(31):JCO2018788620.

14. Basch E, Deal AM, Kris MG, Scher HI, Hudis CA, Sabbatini P, et al. Symptom monitoring with patient-reported outcomes during routine cancer treatment: a randomized controlled trial. J Clin Oncol. 2016;34(6):557-65.

15. Mazariego CJ, M, Chan RJ, Roberts N, Millar L, Anazodo A, Hayes S, Brown B, Saunders C, Webber K, Vardy J, Girgis A, Kocawara B. Priority recommendations for the implementation of patient reported outcomes in clinical cancer care: a Delphi study. J Cancer Surviv. 2021.

16. Kline RM, Arora NK, Bradley CJ, Brauer ER, Graves DL, Lunsford NB, et al. Long-term survivorship care after cancer treatment-summary of a 2017 National Cancer Policy Forum Workshop. J Natl Cancer Inst. 2018;110(12):1300-10.

17. Nathan PC, Daugherty CK, Wroblewski KE, Kigin ML, Stewart TV, Hlubocky FJ, et al. Family physician preferences and knowledge gaps regarding the care of adolescent and young adult survivors of childhood cancer. J Cancer Surv. 2013;7(3):275-82.

18. Klemp JK, CJ, Lowry B, Long T, Bush C, Alsman K, Krebill H, Peereboom D, Overholser L, Greiner KA. Informing the delivery of cancer survivorship care in rural primary care practice. Journal of cancer survivorship : research and practice. J Cancer Surviv. 2021.

19. Jayzona AS, SM, Kim J, Schapira L. Educational innovation to integrate cancer survivorship to primary care: course evaluation and learner outcomes. J Cancer Surviv. 2021.

Publisher's note Springer Nature remains neutral with regard to jurisdictional claims in published maps and institutional affiliations. 